\title{
Numerical Analysis of Flattened Brazilian Disc Test Based on the Cusp Catastrophe Theory
}

\author{
Min Wang ${ }^{1,2}$ and Ping Cao \\ ${ }^{1}$ School of Resources and Safety Engineering, Central South University, Changsha, Hunan 410083, China \\ ${ }^{2}$ Hunan Provincial Key Laboratory of Shale Gas Resource Utilization, Hunan University of Science and Technology, \\ Xiangtan, Hunan 411201, China \\ Correspondence should be addressed to Min Wang; michaelwong307@outlook.com
}

Received 20 April 2016; Revised 11 June 2016; Accepted 26 June 2016

Academic Editor: Xiao-Qiao He

Copyright (C) 2016 M. Wang and P. Cao. This is an open access article distributed under the Creative Commons Attribution License, which permits unrestricted use, distribution, and reproduction in any medium, provided the original work is properly cited.

\begin{abstract}
The Brazilian disc test is a simple and useful technique to determine the tensile strength of rock materials. By using FLAC3D, 63 numerical simulations in total were performed when flattened Brazilian disc coefficient and Poisson's ratio were different. Based on Griffith theory, the corresponding FISH language was compiled to record the Griffith equivalent stress. Through analysis of numerical simulation results, it is indicated that fracture plane was not the plane going through center of the Brazilian disc, which was in good agreement with the references. In addition, the flattened Brazilian disc coefficients had greater influence on tensile strength than Poisson's ratio. Based on cusp catastrophe theory, the flattened Brazilian disc coefficient should not exceed 0.035 for the flattened Brazilian disc tests. Consequently, a tensile strength empirical formula considering flattened Brazilian disc coefficient by utilizing the flattened Brazilian disc test was established, which was $\sigma_{\mathrm{t}}=0.9993 \exp (-11.65 \varepsilon)(2 p / \pi D t), \varepsilon \leq 0.035$.
\end{abstract}

\section{Introduction}

The Brazilian disc test is a useful technique to determine the tensile strength of rock materials [1-6]; the Brazilian disc test has attracted the attention of a large number of scholars due to its extensive practical importance in engineering application. There are many studies on the Brazilian disc test in theory analysis, laboratory test, and numerical simulations. Jianhong et al. [7] analyzed the plane stress distribution of the Brazilian disc test; the tensile elastic modulus of a rock can be obtained by the results of theory analysis. Serati et al. [8] investigated the double Fourier series technique to construct an elastic stress filed in a cylindrical subject to lateral boundary loads, and this method was verified against available elastic solutions for axisymmetric and nonaxisymmetric engineering problems such as Brazilian tensile strength and point load strength. With regard to the experiments for the Brazilian test, Tan et al. [9] conducted a series of Brazilian tests on Monsel slate considering different foliation-loading angles, fracture patterns and strength of samples were analyzed, and how the microparameters influence the bearing capacity and failure modes of Brazilian disc tests for anisotropic rocks was revealed. Liu et al. [10] investigated the mechanical tensile behavior of Beisha granite with different test methods, especially the damage evolution process. It was revealed that, in direct tensile testing, the $\mathrm{AE}$ events accumulated mainly along the failure surface, whereas in indirect tests the location and variation of $\mathrm{AE}$ events were more complex. In the field of numerical simulations, Riera et al. [6] utilize the discrete element method (DEM) to simulate the Brazilian test, and it was concluded that specifications for the splitting test of quasifragile materials should be examined under the light of recent advances in fracture crack propagation and dynamic rupture, properly considering the influence of the not-yet-clearlydefined material properties and geometry of the strip. Yang and Huang [11] constructed a model for Brazilian disc splitting test using PFC2D, and then it was used to simulate Brazilian splitting test for jointed rock mass specimens and specimen containing a central straight notch, and the influences of joint angles on tensile strength and failure modes were analyzed. 
However, three-dimension effects of Brazilian test can influence the results [12], and hence the thickness $(t) /$ diameter $(D)$ ratio should be considered in the Brazilian disc. ASTM suggested that the thickness $(t)$ /diameter $(D)$ ratio ranged between 0.2 and 0.75 [13], while ISRM recommended that $t / D$ ratio should be 0.5 [14]. In addition, the deformation on loading location would occur, and the loading mode and stress distribution also changed, which had given rise to the large error by utilizing Brazilian tests to obtain the tensile strength of rock materials. Obviously, the deformation on loading location is inevitable. Hence, reducing deformation on loading location would be the key to improving the results accuracy utilizing the Brazilian test, and the flattened Brazilian test would be a good alternative.

The flattened Brazilian test has been a popular method in recent years to determine the tensile strength of rock materials [15-19]. Wang et al. [20] conducted theory analysis, and the stress distribution for flattened Brazilian test was obtained; moreover, the numerical simulations of flattened Brazilian test were performed, and the formulas for elastic modulus, tensile strength, and fracture toughness of rocks were derived. Lin et al. [21] analyzed the three-dimensional effects in the flattened Brazilian test through numerical simulation, and the empirical formula of the flattened Brazilian test was proposed.

In this paper, the flattened Brazilian disc coefficient was used to measure the size of the flattened Brazilian disc plane instead of the loading angle. The flattened Brazilian disc with different flattened Brazilian disc coefficient was constructed in FLAC3D to simulate the flattened Brazilian tests. The FISH language was compiled to illustrate the Griffith equivalent stress of the flattened Brazilian discs, and the possible fracture planes of the flattened Brazilian discs were analyzed. Consequently, the empirical formula of tensile strength using flattened Brazilian tests was put forward.

\section{Numerical Simulation of Flattened Brazilian Disc Test}

2.1. Flattened Brazilian Disc Coefficient $\varepsilon$. In most references, the loading angle was used to describe the size of loading plane; however, the angle is much complicated to measure in practice. Hence, in this paper, the flattened Brazilian disc coefficient $\varepsilon$ was employed to depict the size of loading plane, displayed in Figure 1.

The flattened Brazilian disc coefficient can be expressed as the following equation:

$$
\varepsilon=\frac{B C}{O B}=1-\frac{D C}{A B}
$$

where $\varepsilon$ is the flattened Brazilian disc coefficient; $D C$ is the height of the flattened Brazilian disc; and $A B$ is the diameter of the disc. Based on (1), it is obvious that the flattened Brazilian disc coefficient can be measured more easily than the loading angle.

2.2. Numerical Simulations Construction and Mechanical Parameters. To study the influence of the flattened Brazilian

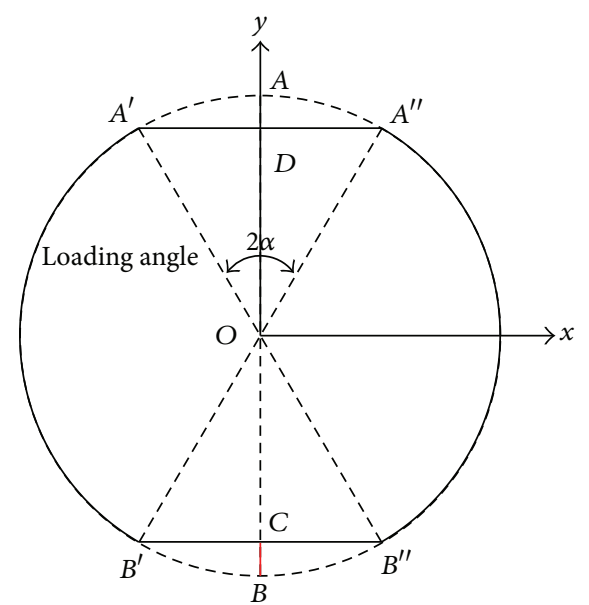

Figure 1: The flattened Brazilian disc coefficient.

disc coefficient on the flattened Brazilian disc test, the commercial software FLAC3D was utilized. To construct the numerical simulation model, its modeling and meshing were accomplished in ANSYS with Solid185 zone type; subsequently, the constructed numerical simulation models were introduced into FLAC3D, the numerical simulation models with different flattened Brazilian disc coefficient were constructed (Figure 2), the flattened Brazilian disc coefficient ranged from 0 to 0.04 with spacing of 0.005 , diameter of Brazilian discs was $0.05 \mathrm{~m}$, and their thickness was $0.05 \mathrm{~m}$.

The uniaxial compression loading was applied on the flattened plane of the flattened Brazilian disc directly, and its loading rate was $5 e-9 \mathrm{~m} / \mathrm{step}$. Simultaneously, the related FISH program [22] was compiled to record the applied load $p$. When the mechanical ratio fell below $1 e-5$, then numerical simulations ended. The numerical simulation model was elastic model. Due to having no influence of Young's modulus $E$ on the stress distribution [23, 24], Young's modulus for all numerical simulation models was $100 \mathrm{GPa}$. Poisson's ratio included $0.1,0.15,0.2,0.25,0.3,0.35$, and 0.4 , and shear modulus $G$ of numerical simulation models can be calculated based on the following equation:

$$
G=\frac{E}{2(1+v)},
$$

where $E$ is Young's modulus and $v$ is Poisson's ratio.

Through combination of different flattened Brazilian disc coefficient (9 types) and Poisson's ratio (7 types), 63 numerical simulations in total were performed.

\section{Numerical Simulation Results Analysis}

3.1. Fracture Plane Analysis of the Brazilian Disc Test. For most rock materials, they belong to brittle materials, and the fracture mechanism can be explained by Griffith theory $[25,26]$. Moreover, $\mathrm{Yu}$ and $\mathrm{Xu}$ [27] suggested that the location of the maximum equivalent stress $\sigma_{\mathrm{G}}$ was the fracture plane location, and the key of finding the fracture plane was determining location of the maximum equivalent stress. Based on 


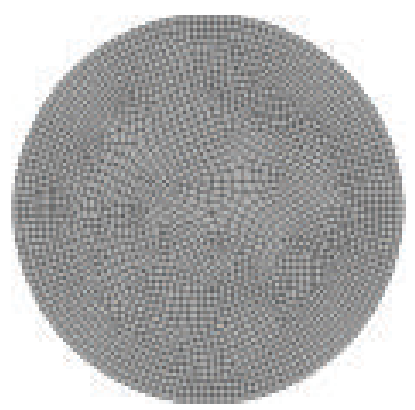

(a) 0.01

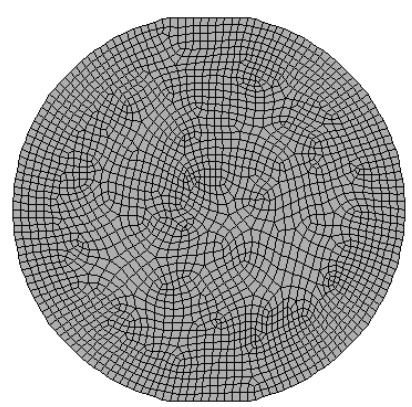

(b) 0.02

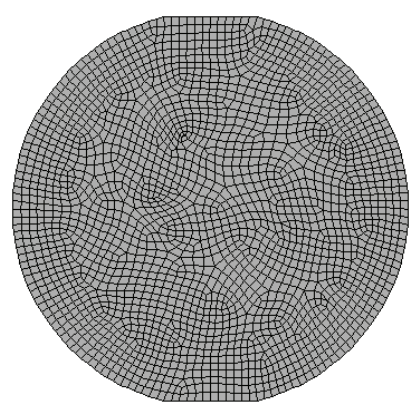

(c) 0.03

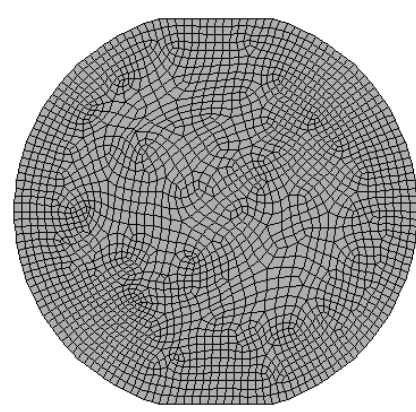

(d) 0.04

FIGURE 2: Some flattened Brazilian discs with different flattened Brazilian disc coefficient.

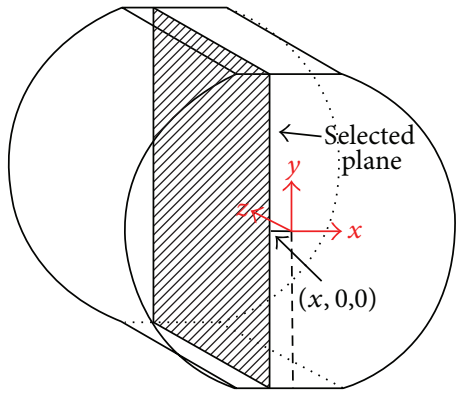

Figure 3: A selected plane parallel to $y z$-plane and with $x$ coordinate.

Griffith criterion, the Griffith equivalent stress $\sigma_{\mathrm{G}}$ can be expressed as follows:

$$
\sigma_{\mathrm{G}}= \begin{cases}-\frac{\left(\sigma_{1}-\sigma_{3}\right)^{2}}{\sigma_{1}+\sigma_{3}}, & \sigma_{1}+3 \sigma_{3} \geq 0, \\ \sigma_{3}, & \sigma_{1}+3 \sigma_{3}<0\end{cases}
$$

where $\sigma_{1}$ is the maximum principal stress, $\sigma_{3}$ is the minimum principal stress, and $\sigma_{\mathrm{G}}$ is the Griffith equivalent stress.

In order to explore the location of fracture plane of the Brazilian disc test, the corresponding FISH language was compiled to calculate the average Griffith equivalent stress $\sigma_{\mathrm{GP}}$ of the selected plane, which was parallel to $y z$-plane and with $x$-coordinate, showed in Figure 3.

To determine the possible fracture plane during loading process, four numerical simulation results were taken as examples to illustrate the possible fracture plane. For convenient comparison of the numerical simulation results, contour of the dimensionless ratio $\sigma_{\mathrm{G}} /(2 p / \pi D t)$ was displayed in FLAC3D by compiling the FISH language, and the dimensionless ratio $\sigma_{\mathrm{GP}} /(2 p / \pi D t)$ of the selected plane with different $x$-coordinate is displayed in Figure 4.

As shown in Figure 4, the maximum dimensionless ratio $\sigma_{\mathrm{GP}} /(2 p / \pi D t)$ of the selected plane was not in the $y z$ plane, which meant that the possible fracture plane was not the plane going through the center of Brazilian discs. For instance, when the flattened Brazilian disc coefficient was 0.04 (Figure $4(\mathrm{~d}))$, the maximum ratio $\sigma_{\mathrm{GP}} /(2 p / \pi D t)$ of the selected plane was not the plane going through the center of Brazilian disc ( $x$-coordinate of the selected plane was $0 \mathrm{~mm}$, and $\sigma_{\mathrm{GP}} /(2 p / \pi D t)$ was 0.4545$)$, but the plane going through the compression plane ends $(x$-coordinate of the selected plane was $-4 \mathrm{~mm}$, and ratio $\sigma_{\mathrm{GP}} /(2 p / \pi D t)$ was $0.4721)$. The larger the ratio $\sigma_{\mathrm{GP}} /(2 p / \pi D t)$ was, the larger the average Griffith equivalent stress $\sigma_{\mathrm{GP}}$ was; consequently, the possible fracture plane would be the plane with $-4 \mathrm{~mm} x$ coordinate when the flattened Brazilian disc coefficient was 0.04 and Poisson's ratio was 0.1. Based on numerical simulation results, it was implied that the possible fracture plane possibly occurred on the plane going through the compression plane ends $\left(A^{\prime}, B^{\prime}\right.$ and $\left.A^{\prime \prime}, B^{\prime \prime}\right)$, displayed in Figure 5.

The numerical simulation results indicated that the location of the maximum Griffith equivalent stress is not the center of the Brazilian disc; that is, the cracks would not initiate from the center of the flattened Brazilian discs, which cannot guarantee the accuracy of the tensile strength by utilizing the Brazilian discs test. Through analysis of the numerical simulation results, it is suggested that the accuracy of the tensile strength difference decreases with increasing of flattened Brazilian disc coefficient.

Moreover, these results were also verified by the study by You and Su [28]. It is observed that the fracture plane is not going through the center of Brazilian discs, and these results were in good agreement with the observation of $[29,30]$. Changing of the flattened Brazilian disc coefficient influenced stress distribution of the flattened Brazilian disc, which had given rise to the fracture plane away from the center of Brazilian discs.

Both numerical simulation results and laboratory tests [28-30] had shown that fracture plane location would not occur along the plane going through the center of Brazilian disc, but it had more possibly gone through the compression plane ends. Thus, when adopting the Brazilian disc test to determine the tensile strength, taking the Griffith equivalent stress of Brazilian disc center as the tensile strength of rock materials would not be so accurate in the flattened Brazilian disc tests. Hence, it was necessary to calibrate the empirical formula of the tensile strength by adopting the flattened Brazilian disc test.

3.2. Empirical Formula of Flattened Brazilian Disc Tests. In accordance with the aforementioned numerical simulations results, the fracture plane deviated from the center of 

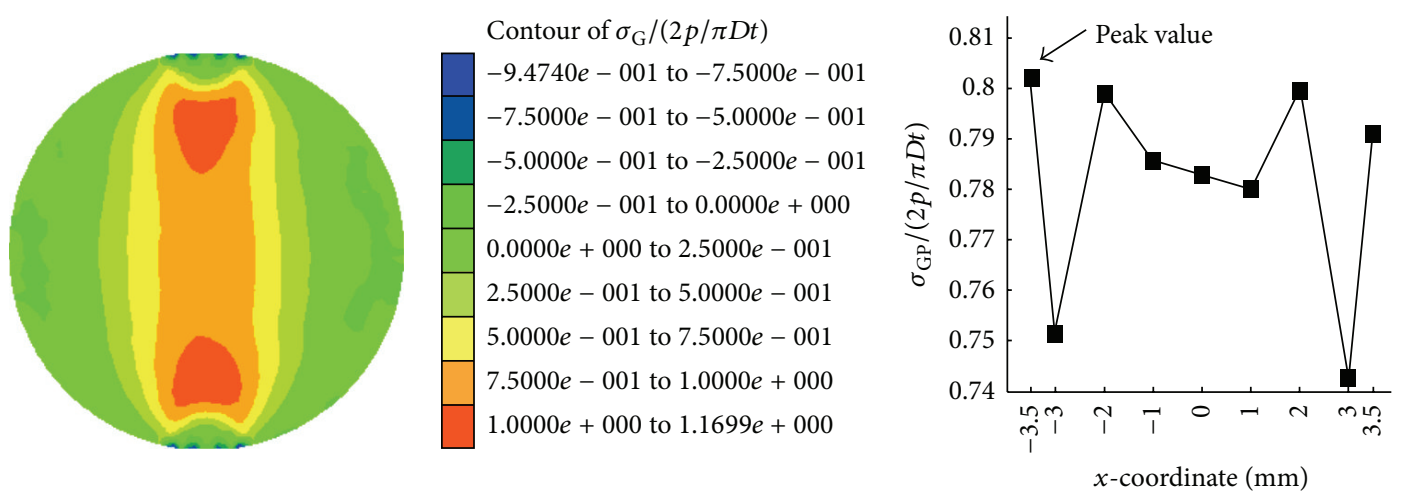

(a) Flattened Brazilian disc coefficient is 0.01
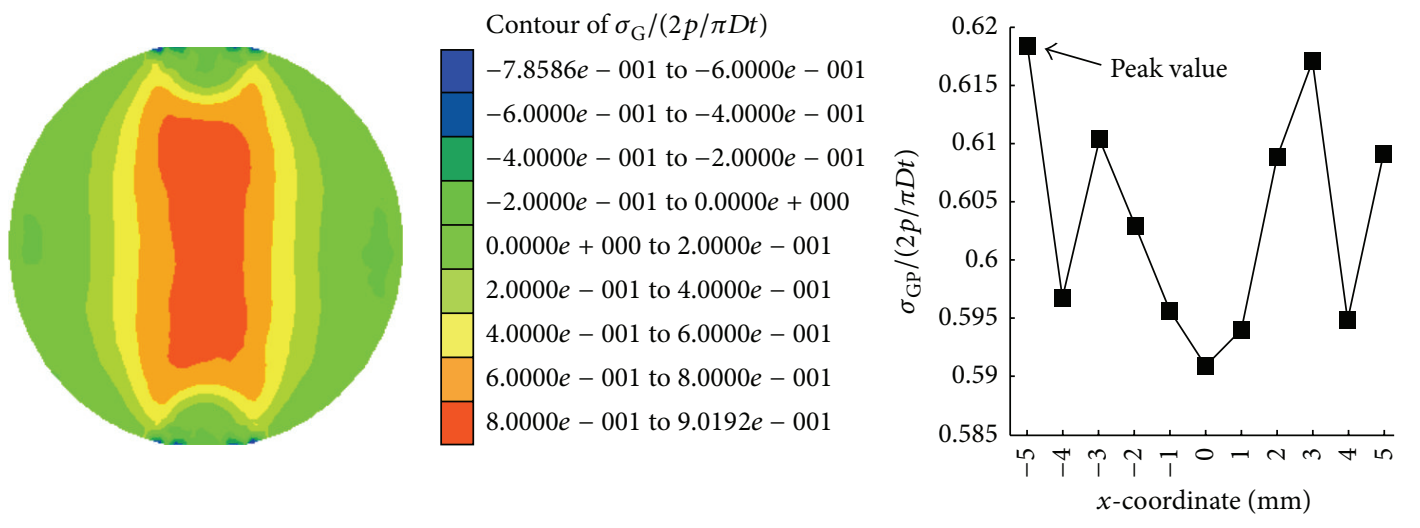

(b) Flattened Brazilian disc coefficient is 0.02
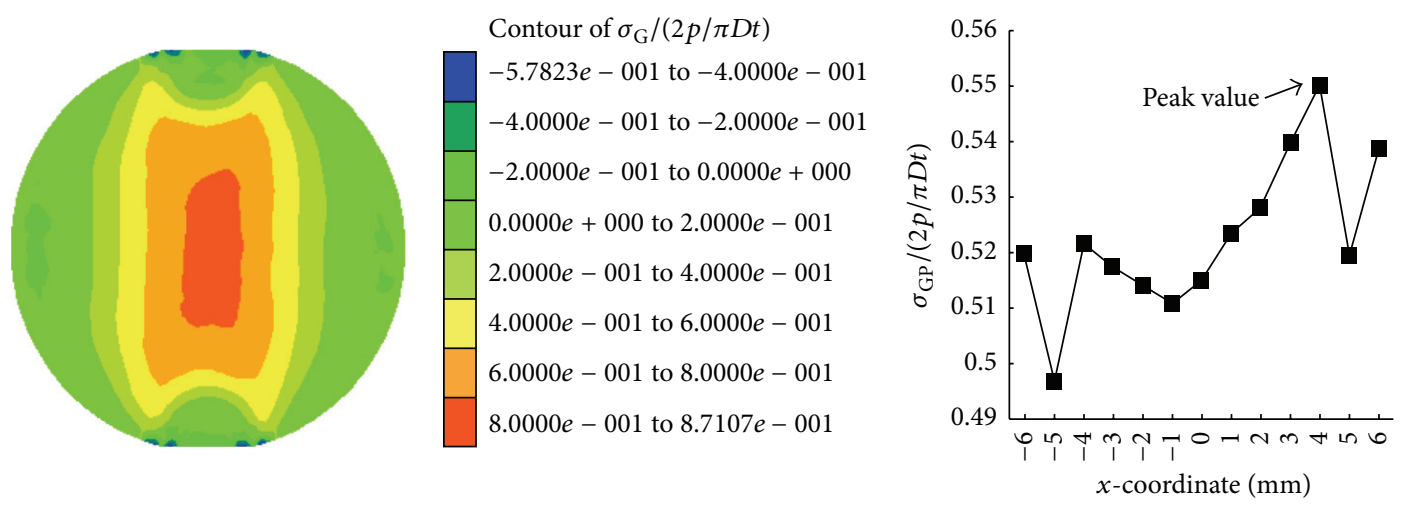

(c) Flattened Brazilian disc coefficient is 0.03
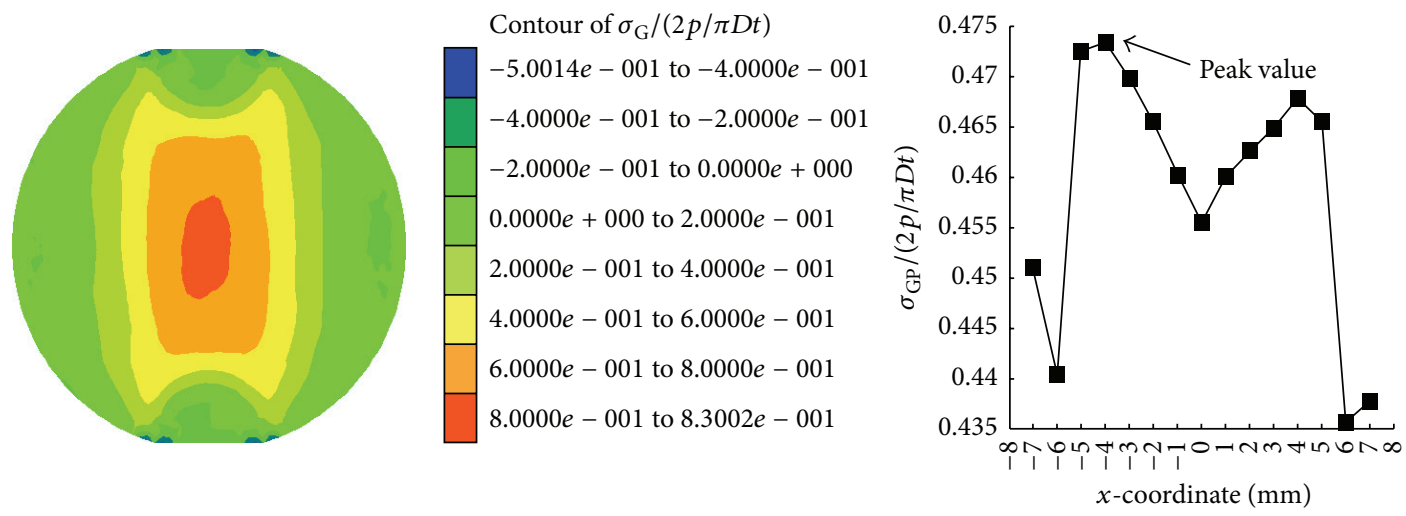

(d) Flattened Brazilian disc coefficient is 0.04

FIGURE 4: Contour of the dimensionless ratio $\sigma_{\mathrm{G}} /(2 p / \pi D t)$ and ratio $\sigma_{\mathrm{GP}} /(2 p / \pi D t)$ with different $x$-coordinate when Poisson's ratio $v$ is 0.1 . 


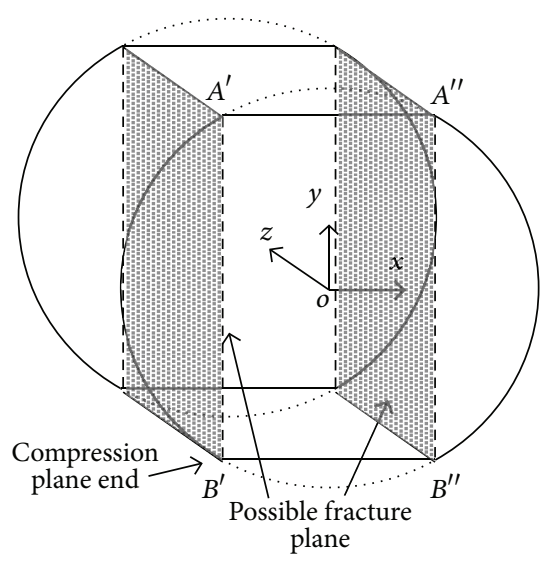

Figure 5: Possible fracture plane.

Brazilian discs; hence, taking the Griffith equivalent stress of Brazilian discs' center as the tensile strength of rock materials was not reasonable. However, taking the maximum Griffith equivalent stress $\sigma_{\mathrm{G}-\max }$ of the flattened Brazilian disc would be more accurate.

As discussed previously, the stress distribution changed with increasing the flattened Brazilian disc coefficient, and the possible fracture plane was not the plane going through the Brazilian discs center; in other words, the maximum Griffith equivalent stress location changed as well, and the correlation of the tensile strength and the applied load $p$ should be calibrated. The correlation between the maximum Griffith equivalent stress $\sigma_{\mathrm{G}-\max }$ of the center plane and the applied load $p$ can be expressed as follows:

$$
\sigma_{\mathrm{t}}=\sigma_{\mathrm{G}-\max }=k^{*} \frac{2 p}{\pi D t},
$$

where $\sigma_{\mathrm{t}}$ is the tensile strength of rock materials by using the flattened Brazilian disc test, $\sigma_{\mathrm{G}-\max }$ is the maximum Griffith equivalent stress of the Brazilian disc, $p$ is the applied load, $D$ is the diameter of Brazilian discs, $t$ is the thickness of Brazilian discs, and $k^{*}$ is the correction coefficient.

In order to explore influence of Poisson's ratio and the flattened Brazilian disc coefficient on the correction coefficient $k^{*}$, its changing trend with increasing Poisson's ratio and the Brazilian disc coefficient are displayed in Figure 6, respectively.

As shown in Figure 6, the influence of Poisson's ratio on the correction coefficient $k^{*}$ was not obvious (in Figure 6(a)). When the flattened Brazilian disc coefficient was constant, the correction coefficient $k^{*}$ remained at a stable level with variation of Poisson's ratio. For example, the flattened Brazilian disc coefficient was 0.02 , and the correction coefficients $k^{*}$ were $0.7467,0.7499,0.7731,0.7833,0.7903,0.7638$, and 0.7765 when Poisson's ratios were $0.1,0.15,0.2,0.25,0.3,0.35$, and 0.4 , separately. However, the flattened Brazilian disc coefficient influenced the correction coefficient $k^{*}$ a lot (shown in Figure $6(\mathrm{~b})$ ), and $k^{*}$ noticeably changed with increasing the flattened Brazilian disc coefficient.

Through analysis of Figure 6(b), the tensile strength was influenced strongly by the flattened Brazilian disc coefficient; therefore, it was necessary to determine the maximum flattened Brazilian disc coefficient for avoiding big error when using (4). In order to determine the maximum flattened Brazilian disc coefficient, cusp catastrophe theory [31-37] was adopted. Because Poisson's ratio had little influence on $k^{*}$, Poisson's ratio was neglected in analysis of determining the maximum flattened Brazilian disc coefficient. Subsequently, the average error $e_{\mathrm{ta}}$ of the tensile strength with different flattened Brazilian disc coefficient was introduced to express the error of adopting (4) in the Brazilian disc test, and the average error $e_{\mathrm{ta}}$ can be defined as follows:

$$
\begin{aligned}
e_{\mathrm{ta}} & =\frac{\sum_{i=1}^{n}\left(\left|\sigma_{\mathrm{G}-\max i}-2 p_{i} / \pi D t\right| /\left(2 p_{i} / \pi D t\right)\right)}{n} \\
& =\frac{\sum_{i=1}^{n}\left|k_{i}^{*}-1\right|}{n},
\end{aligned}
$$

where $e_{\mathrm{ta}}$ is the average error of tensile strength with different flattened Brazilian disc coefficient, $p_{i}$ is the maximum applied load, $D$ is the diameter of Brazilian discs, $t$ is the thickness of Brazilian discs, $k_{i}^{*}$ is the correction coefficient, and $n$ is the number of Poisson's ratio types ( $n$ is 7 in this paper).

Through analysis of Figure 6 and (5), it is found that the calculation error would increase with increasing of the flattened Brazilian disc coefficient. The large flattened Brazilian disc coefficient would result in the crack initiation location far away from the flattened Brazilian disc center; thereafter, a large error would occur when using the flattened Brazilian disc test to determine the tensile strength of rock materials. In this paper, the cusp catastrophe theory was utilized to determine the maximum flattened Brazilian disc coefficient. The correlation of the error $e_{\mathrm{ta}}$ and the flattened Brazilian disc coefficient $\varepsilon$ can be expressed as the cusp catastrophe function $e_{\mathrm{ta}}(\varepsilon)$. According to cusp catastrophe theory, the function $e_{\mathrm{ta}}(\varepsilon)$ can be written as follows:

$$
e_{\mathrm{ta}}(\varepsilon)=\varepsilon^{4}+u \varepsilon^{2}+v \varepsilon
$$

The potential function $e_{\mathrm{ta}}(\varepsilon)$ can be plotted as shown in Figure 7.

As shown in Figure 7, cusp catastrophe function $e_{\mathrm{ta}}(\varepsilon)$ consists of three parts: up lobe, middle lobe, and down lobe. Based on cusp catastrophe theory, the characteristics of cusp catastrophe function $e_{\mathrm{ta}}(\varepsilon)$ were controlled by $u$ and $v$, which formed the control variable plane. The stability of cusp catastrophe function $e_{\mathrm{ta}}(\varepsilon)$ was controlled by the bifurcation set $\Delta=8 u^{3}+27 v^{2}$. If $8 u^{3}+27 v^{2} \geq 0$, the function $e_{\mathrm{ta}}(\varepsilon)$ was stable. While $8 u^{3}+27 v^{2}<0$, the function $e_{\mathrm{ta}}(\varepsilon)$ was unstable. In other words, if $8 u^{3}+27 v^{2}<0$, (6) describing the correlation of the tensile strength $\sigma_{\mathrm{t}}$ and the correction coefficient $k^{*}$ was not stable, and catastrophe change would occur. Thus, a big error would occur when using (6) to determine the tensile strength of rock materials in the flattened Brazilian disc test.

To determine the maximum flattened Brazilian disc coefficient, a series of data sets $\left\{\left(e_{\mathrm{ta}}(\varepsilon)_{1}, \varepsilon_{1}\right),\left(e_{\mathrm{ta}}(\varepsilon)_{2}, \varepsilon_{2}\right), \ldots\right.$, $\left.\left(e_{\mathrm{ta}}(\varepsilon)_{i}, \varepsilon_{i}\right)\right\}(i=4,5, \ldots, 9)$ were formed firstly. For example, when the maximum flattened Brazilian disc coefficient was 0.015 , the corresponding data set would be $\left\{\left(e_{\mathrm{ta}}(\varepsilon)_{1}, \varepsilon_{1}\right)\right.$, $\left.\left(e_{\mathrm{ta}}(\varepsilon)_{2}, \varepsilon_{2}\right),\left(e_{\mathrm{ta}}(\varepsilon)_{3}, \varepsilon_{3}\right),\left(e_{\mathrm{ta}}(\varepsilon)_{4}, \varepsilon_{4}\right)\right\}$, which meant the flattened Brazilian disc coefficients $\varepsilon_{1}, \varepsilon_{2}, \varepsilon_{3}$, and $\varepsilon_{4}$ were $0,0.005$, 


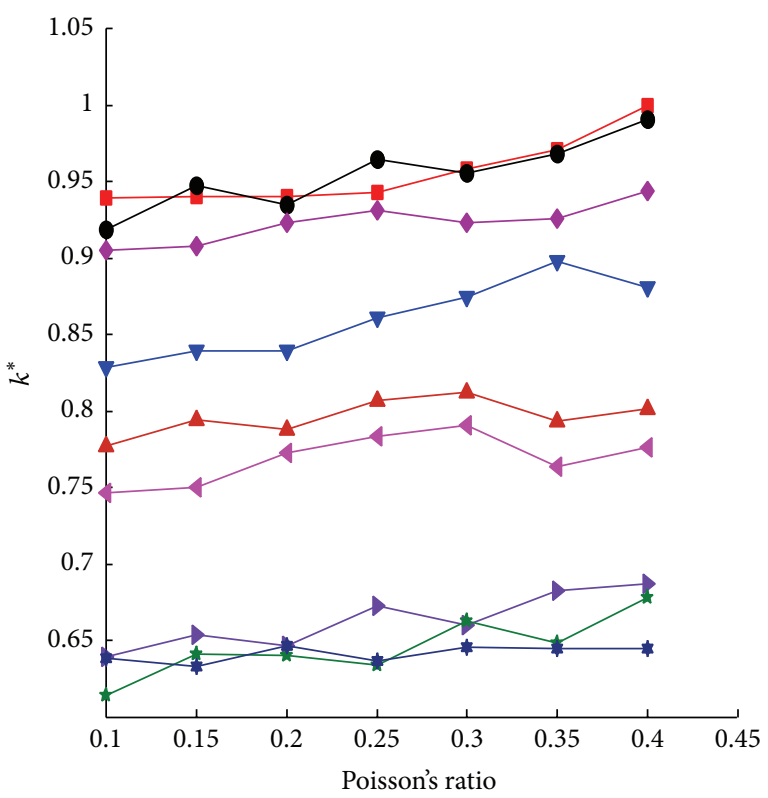

Flattened Brazilian disc coefficient

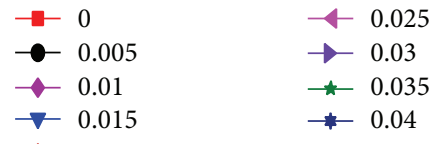

(a)
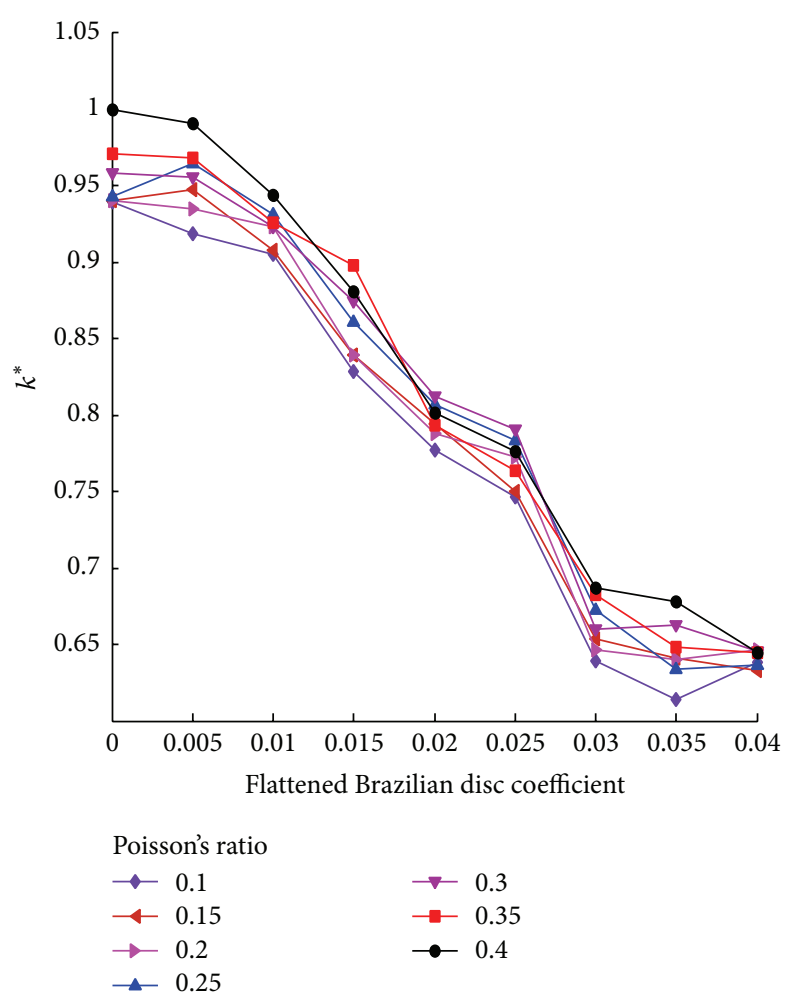

(b)

Figure 6: Influence of Poisson's ratio and flattened Brazilian disc coefficient on the correction coefficient $k^{*}$.

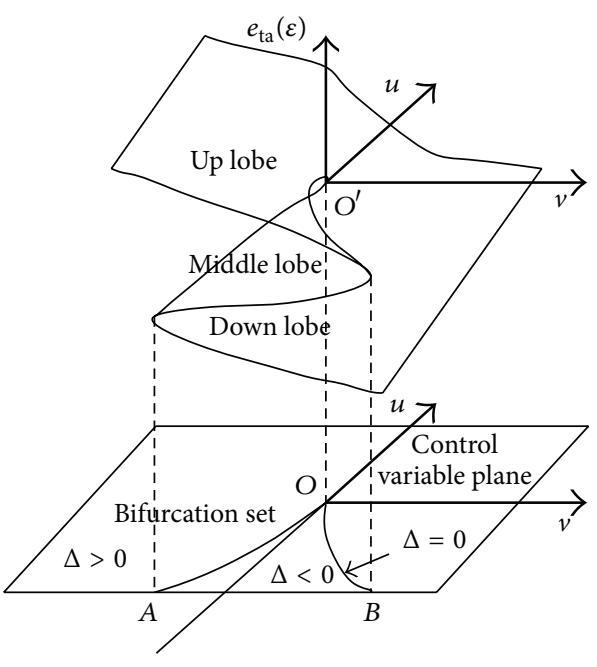

FIGURE 7: Cusp catastrophe function $e_{\mathrm{ta}}(\varepsilon)$.

0.01 , and 0.015 , respectively. Then, the least square fittings of the data sets $\left\{\left(e_{\mathrm{ta}}(\varepsilon)_{1}, \varepsilon_{1}\right),\left(e_{\mathrm{ta}}(\varepsilon)_{2}, \varepsilon_{2}\right), \ldots,\left(e_{\mathrm{ta}}(\varepsilon)_{i}, \varepsilon_{i}\right)\right\}(i=$ $4,5, \ldots, 9)$ were conducted adopting (4). Subsequently, different groups of $u$ and $v$ were obtained when the maximum flattened Brazilian disc coefficient was different, and the corresponding bifurcation sets $\Delta=8 u^{3}+27 v^{2}$ were calculated. When $\Delta=8 u^{3}+27 v^{2}<0$, then the catastrophe change happened, and then the maximum flattened Brazilian disc coefficient was determined.

Based on the method above, a series of $u, v$, and $8 u^{3}+27 v^{2}$ were calculated when the maximum flattened Brazilian disc coefficient was different (Table 1), and Figure 8 displays the variation of $\Delta=8 u^{3}+27 v^{2}$ when $i$ is 8 and 9 .

Through analysis of Figure $8, \Delta=8 u^{3}+27 v^{2}$ was positive when $i$ was 8 . While $i$ was $9, \Delta=8 u^{3}+27 v^{2}$ was negative; that is to say, cusp catastrophe function $e_{\mathrm{ta}}(\varepsilon)$ for data set $\left\{\left(e_{\mathrm{ta}}(\varepsilon)_{1}, \varepsilon_{1}\right),\left(e_{\mathrm{ta}}(\varepsilon)_{2}, \varepsilon_{2}\right), \ldots,\left(e_{\mathrm{ta}}(\varepsilon)_{8}, \varepsilon_{8}\right)\right\}$ was stable, which suggested that catastrophe change of error will not occur when using (4) to determine tensile strength. While data set $\left\{\left(e_{\mathrm{ta}}(\varepsilon)_{1}, \varepsilon_{1}\right),\left(e_{\mathrm{ta}}(\varepsilon)_{2}, \varepsilon_{2}\right), \ldots,\left(e_{\mathrm{ta}}(\varepsilon)_{9}, \varepsilon_{9}\right)\right\}$ was not stable, the catastrophe change of error occurred; hence, the data $\left(e_{\mathrm{ta}}(0.04), 0.04\right)$ caused the catastrophe change, and the flattened Brazilian disc coefficient should be less than 0.04 . However, for accuracy of the tensile strength when using (4), flattened Brazilian disc coefficient should not exceed 0.035, which was in good agreement with the study by Lin et al. [21].

Because of little influence of Poisson's ratio on the correction coefficient $k^{*}$, the tensile strength determined by (4) without consideration of Poisson's ratio was acceptable. To establish correlation of flattened Brazilian disc coefficient $\varepsilon$ and the correction coefficient $k^{*}$, the data was used when flattened Brazilian disc coefficient ranged from 0 to 0.035 , and the average correction coefficient $k_{\mathrm{a}}^{*}$ was calculated when flattened Brazilian disc coefficients were different, listed in Table 2. 
TABLE 1: Different $u, v$, and $8 u^{3}+27 v^{2}$ when maximum flattened Brazilian disc coefficients are different.

\begin{tabular}{lcccccc}
\hline$i$ & 4 & 5 & 6 & 7 & 8 & 9 \\
\hline Maximum flattened & 0.015 & 0.020 & 0.025 & 0.030 & 0.035 & 0.040 \\
Brazilian disc coefficient & 0.548 & 141.100 & 23.990 & 125.600 & 48.030 \\
$u$ & 8.834 & 7.2100 & 8.922 & 7.091 & 8.697 & 16.580 \\
$v$ & $>0$ & $>0$ & $>0$ & $>0$ & $>0$ & $<0$ \\
$\Delta=8 u^{3}+27 v^{2}$ & & & &
\end{tabular}

TABLE 2: Average correction coefficient $k_{\mathrm{a}}^{*}$ when flattened Brazilian disc coefficients are different.

\begin{tabular}{lcccccccc}
\hline Correction coefficient $\left(k^{*}\right)$ & \multicolumn{7}{c}{ Flattened Brazilian disc coefficient $(\varepsilon)$} \\
& 0 & 0.005 & 0.010 & 0.015 & 0.020 & 0.025 & 0.030 & 0.035 \\
\hline Poisson's ratio $(v)$ & & & & & & \\
0.10 & 0.9398 & 0.9188 & 0.9057 & 0.8288 & 0.7772 & 0.7467 & 0.6393 & 0.6393 \\
0.15 & 0.9404 & 0.9473 & 0.9080 & 0.8398 & 0.7939 & 0.7499 & 0.6537 & 0.6537 \\
0.20 & 0.9402 & 0.9350 & 0.9231 & 0.8391 & 0.7879 & 0.7731 & 0.6461 & 0.6461 \\
0.25 & 0.9428 & 0.9650 & 0.9316 & 0.8607 & 0.8086 & 0.7833 & 0.6723 & 0.6723 \\
0.30 & 0.9586 & 0.9558 & 0.9231 & 0.8750 & 0.8126 & 0.7903 & 0.6596 & 0.6596 \\
0.35 & 0.9712 & 0.9685 & 0.9256 & 0.8977 & 0.7934 & 0.7638 & 0.6823 & 0.6823 \\
0.40 & 1.0002 & 0.9911 & 0.9440 & 0.8813 & 0.8014 & 0.7765 & 0.6874 & 0.6874 \\
\hline Average correction coefficient $\left(k_{\mathrm{a}}^{*}\right)$ & 0.9562 & 0.9542 & 0.9230 & 0.8603 & 0.7962 & 0.7691 & 0.6630 & 0.6545 \\
\hline
\end{tabular}

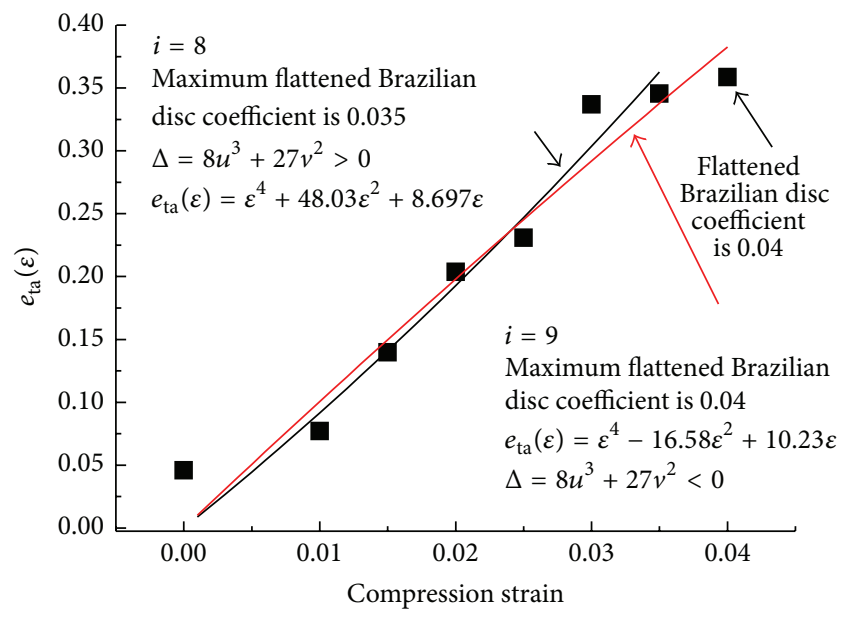

FIGURE 8: $8 u^{3}+27 v^{2}$ changing trend when maximum flattened Brazilian disc coefficient is 0.035 and 0.04 .

Based on the data in Table 2, correlation of $k_{\mathrm{a}}^{*}$ and flattened Brazilian disc coefficient $\varepsilon$ was constructed via the least square fitting method, shown in Figure 9.

Consequently, correlation of the average correction coefficient and flattened Brazilian correction coefficient can be expressed as follows:

$$
k_{\mathrm{a}}^{*}=0.9993 \exp (-11.65 \varepsilon) .
$$

Due to little influence of Poisson's ratio on the correction coefficient $k^{*}, k^{*}$ in (4) can be replaced by $k_{\mathrm{a}}^{*}$; combining (4)

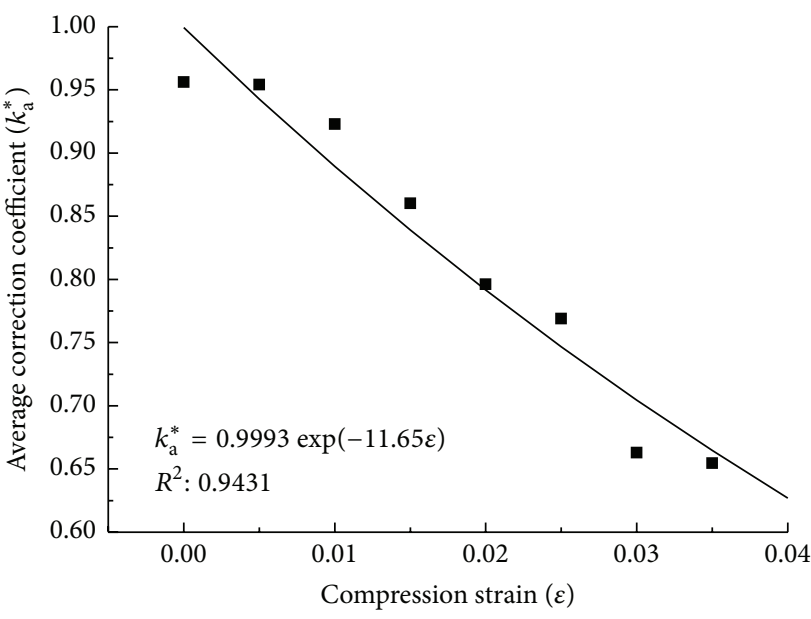

FIGURE 9: Correlation of the average correction coefficient and flattened Brazilian disc coefficient.

and (7), the tensile strength formulation of the Brazilian disc test can be denoted as follows:

$$
\sigma_{\mathrm{t}}=0.9993 \exp (-11.65 \varepsilon) \cdot \frac{2 p}{\pi D t},
$$

where $\varepsilon$ is the flattened Brazilian disc coefficient $(\varepsilon \leq 0.035)$, $\sigma_{\mathrm{t}}$ is the tensile strength, $p$ is the applied load, $D$ is the diameter of Brazilian disc, and $t$ is the thickness of Brazilian disc.

Based on the numerical simulation results, the tensile strength adopting the flattened Brazilian disc test with variation flattened Brazilian disc coefficient is proposed. Moreover, flattened Brazilian disc coefficient is easily obtained 
during the Brazilian disc test compared to loading angle; hence, the empirical tensile strength equation is workable, and it could be adopted to estimate the tensile strength in the flattened Brazilian disc test.

\section{Discussion}

The tensile strength is a key mechanical parameter for rock materials, which plays a dominant role in rock engineering. Both direct method and indirect method were used to determine the tensile strength of rock materials; however, the direct method is time-consuming and hard-conducting. Thereafter, the indirect method was more widely used to obtain the tensile strength of rock materials compared to the direct method.

The Brazilian disc test is one of the most widely used indirect methods, whereas some scholars found that the loading location was smashed and the crack did not initiate from the center of the Brazilian disc due to the stress concentration in the loading location, which decrease the accuracy of the tensile strength by using the Brazilian disc test. It is because the most important point of the Brazilian disc test is the crack initiation from the center of the Brazilian disc center. To increase the accuracy of the tensile strength of the Brazilian disc test, some new Brazilian disc tests were proposed, and the flattened Brazilian disc test was one of them.

In order to obtain accurate tensile strength of rock materials by utilizing the flattened Brazilian disc test, the shape parameter of the flattened Brazilian disc was defined as the flattened Brazilian disc coefficient. Then, 63 numerical simulations in total were performed, and the related FISH language was applied to obtain the Griffith equivalent stress based on the Griffith theory. Through analysis of the numerical simulation results, it is found that the crack initiation location (the maximum Griffith equivalent stress location) deviates from the center of the flattened Brazilian disc center. Moreover, the corresponding tensile strength difference becomes larger with increasing of the flattened Brazilian disc coefficient. Thus, it is necessary to determine the appropriate value of the flattened Brazilian disc coefficient to avoid large error between the experimental results and the true value. In this paper, the cusp catastrophe theory was adopted to determine the maximum flattened Brazilian disc coefficient. Based on the cusp catastrophe theory, the flattened Brazilian disc coefficient should be less than 0.035 . Additionally, an empirical formula was proposed evaluating the tensile strength of rock materials by using the flattened Brazilian disc test.

The numerical simulation is mainly used in this paper, the numerical simulation result was not verified by the experimental results, and it lacks further experimental study. To validate the numerical simulation results, the experiments study on the flattened Brazilian disc test would be our next tasks.

\section{Conclusions}

In this paper, the flattened Brazilian disc tests were conducted, through numerical simulations results analysis, the fracture plane locations of flattened Brazilian disc were determined, and, finally, the tensile strength empirical equation considering flattened Brazilian disc coefficient was obtained; the main conclusions of this paper were as follows:

(1) Through numerical simulations analysis, it was suggested that the fracture plane location was not the plane going through the center of Brazilian discs with increasing flattened Brazilian disc coefficient; it was the plane going through the compression plane ends.

(2) Combining numerical simulation results, an equation for the tensile strength adopting flattened Brazilian disc test was established. Because the maximum Griffith equivalent stress location was not the Brazilian disc center any longer, which was verified by both laboratory tests and numerical simulations, it is necessary to calibrate the empirical formula. The empirical formula for the tensile strength determined by the Brazilian disc test was established, and the empirical equation was $\sigma_{\mathrm{t}}=0.9993 \exp (-11.65 \varepsilon)(2 p / \pi D t), \varepsilon \leq$ 0.035 .

\section{Competing Interests}

The authors declare that there is no conflict of interests regarding the publication of this paper.

\section{Acknowledgments}

This study was funded by the Open Research Fund Program of Hunan Provincial Key Laboratory of Shale Gas Resource Utilization; Hunan University of Science and Technology (Grant no. E21527); the National Natural Science Foundation of China (Grants nos. 51174088, 51174228); the National Basic Research Program of China (Grant no. 013CB035401); and the Fundamental Research Funds for the Central Universities of Central South University (Grants nos. 2015zzts077, 2014zzts055).

\section{References}

[1] E. Komurlu and A. Kesimal, "Evaluation of indirect tensile strength of rocks using different types of jaws," Rock Mechanics and Rock Engineering, vol. 48, no. 4, pp. 1723-1730, 2015.

[2] S. M. Razavi, M. Gonzalez, and A. M. Cuitiño, "General and mechanistic optimal relationships for tensile strength of doubly convex tablets under diametrical compression," International Journal of Pharmaceutics, vol. 484, no. 1-2, pp. 29-37, 2015.

[3] K. Karaman, F. Cihangir, B. Ercikdi, A. Kesimal, and S. Demirel, "Utilization of the Brazilian test for estimating the Uniaxial compressive strength and shear strength parameters," Journal of the Southern African Institute of Mining and Metallurgy, vol. 115, no. 3, pp. 185-192, 2015.

[4] G. Khanlari, B. Rafiei, and Y. Abdilor, "An experimental investigation of the Brazilian tensile strength and failure patterns of laminated sandstones," Rock Mechanics and Rock Engineering, vol. 48, no. 2, pp. 843-852, 2014.

[5] M. J. Mikl-Resch, T. Antretter, M. Gimpel et al., "Numerical calibration of a yield limit function for rock materials by means of the Brazilian test and the uniaxial compression test," International Journal of Rock Mechanics and Mining Sciences, vol. 74, pp. 24-29, 2015. 
[6] J. D. Riera, L. F. F. Miguel, and I. Iturrioz, "Assessment of Brazilian tensile test by means of the truss-like Discrete Element Method (DEM) with imperfect mesh," Engineering Structures, vol. 81, pp. 10-21, 2014.

[7] Y. Jianhong, F. Q. Wu, and J. Z. Sun, "Estimation of the tensile elastic modulus using Brazilian disc by applying diametrically opposed concentrated loads," International Journal of Rock Mechanics and Mining Sciences, vol. 46, no. 3, pp. 568-576, 2009.

[8] M. Serati, H. Alehossein, and D. J. Williams, "3D elastic solutions for laterally loaded discs: generalised Brazilian and point load tests," Rock Mechanics and Rock Engineering, vol. 47, no. 4, pp. 1087-1101, 2014.

[9] X. Tan, H. Konietzky, T. Frühwirt, and D. Q. Dan, "Brazilian tests on transversely isotropic rocks: laboratory testing and numerical simulations," Rock Mechanics and Rock Engineering, vol. 48, no. 4, pp. 1341-1351, 2014.

[10] J. F. Liu, L. Chen, C. P. Wang et al., "Characterizing the mechanical tensile behavior of Beishan granite with different experimental methods," International Journal of Rock Mechanics and Mining Sciences, vol. 69, pp. 50-58, 2014.

[11] S.-Q. Yang and Y.-H. Huang, "Particle flow study on strength and meso-mechanism of Brazilian splitting test for jointed rock mass," Acta Mechanica Sinica, vol. 30, no. 4, pp. 547-558, 2014.

[12] Y. Yu, J. Yin, and Z. Zhong, "Shape effects in the Brazilian tensile strength test and a 3D FEM correction," International Journal of Rock Mechanics and Mining Sciences, vol. 43, no. 4, pp. 623-627, 2006.

[13] "Standard test method for splitting tensile strength of cylindrical concrete specimens," Tech. Rep. ASTM C496, ASTM, Philadelphia, Pa, USA, 1984.

[14] ISRM, "Suggested methods for determining tensile strength of rock materials," International Journal of Rock Mechanics and Mining Sciences \& Geomechanics Abstracts, vol. 15, no. 3, pp. 99103, 1978.

[15] Q. B. Zhang and J. Zhao, "A review of dynamic experimental techniques and mechanical behaviour of rock materials," Rock Mechanics and Rock Engineering, vol. 47, no. 4, pp. 1411-1478, 2014.

[16] R. Chen, F. Dai, J. Qin, and F. Lu, "Flattened Brazilian disc method for determining the dynamic tensile stress-strain curve of low strength brittle solids," Experimental Mechanics, vol. 53, no. 7, pp. 1153-1159, 2013.

[17] Q. Z. Wang, F. Feng, M. Ni, and X. P. Gou, "Measurement of mode I and mode II rock dynamic fracture toughness with cracked straight through flattened Brazilian disc impacted by split Hopkinson pressure bar," Engineering Fracture Mechanics, vol. 78, no. 12, pp. 2455-2469, 2011.

[18] C. Keles and L. Tutluoglu, "Investigation of proper specimen geometry for mode I fracture toughness testing with flattened Brazilian disc method," International Journal of Fracture, vol. 169, no. 1, pp. 61-75, 2011.

[19] Q.-Z. Wang and L. Xing, "Determination of fracture toughness KIC by using the flattened Brazilian disk specimen for rocks," Engineering Fracture Mechanics, vol. 64, no. 2, pp. 193-201, 1999.

[20] Q. Z. Wang, X. M. Jia, S. Q. Kou, Z. X. Zhang, and P.-A. Lindqvist, "The flattened Brazilian disc specimen used for testing elastic modulus, tensile strength and fracture toughness of brittle rocks: analytical and numerical results," International Journal of Rock Mechanics and Mining Sciences, vol. 41, no. 2, pp. 245-253, 2004.
[21] H. Lin, W. Xiong, Z. Y. Xiong, and F. Gong, "Three-dimensional effects in a flattened Brazilian disk test," International Journal of Rock Mechanics and Mining Sciences, vol. 74, pp. 10-14, 2015.

[22] Itasca Consulting Group, Fast Lagrangian Analysis of Continua in 3 Dimensions, User Manual, Version 3.1, Itasca Consulting Group, Minneapolis, Minn, USA, 2004.

[23] Y. Yu, "Questioning the validity of the Brazilian test for determining tensile strength of rocks," Chinese Journal of Rock Mechanics and Engineering, vol. 24, no. 7, pp. 1150-1157, 2005 (Chinese).

[24] Z. L. Xu, Elasticity, Higher Education Press, Beijing, China, 2006 (Chinese).

[25] J. C. Jaeger, N. G. W. Cook, and R. W. Zimmerman, Fundamentals of Rock Mechanics, Blackwell, Oxford, UK, 4th edition, 2007.

[26] A. A. Griffith, "The phenomena of flow and rupture in solids," Philosophical Transactions of the Royal Society of London A, vol. 221, pp. 163-198, 1920.

[27] Y. Yu and Y. L. Xu, "Method to determine tensile strength of rock using flattened Brazilian disk," Chinese Journal of Rock Mechanics and Engineering, vol. 25, no. 7, pp. 1457-1462, 2006 (Chinese).

[28] M. Q. You and C. D. Su, "Experimental study on split test with flatten disk and tensile strength of rock," Chinese Journal of Rock Mechanics and Engineering, vol. 23, no. 18, pp. 3106-3112, 2004 (Chinese).

[29] C. Fairhurst, "On the validity of the 'Brzilian' test for brittle materials," International Journal of Rock Mechanics and Mining Sciences, vol. 46, pp. 421-425, 2009.

[30] J. J. Swab, J. Yu, R. Gamble, and S. Kilczewski, "Analysis of the diametral compression method for determining the tensile strength of transparent magnesium aluminate spinel," International Journal of Fracture, vol. 172, no. 2, pp. 187-192, 2011.

[31] Z.-X. Liu, M. Lan, S.-Y. Xiao, and H.-Q. Guo, "Damage failure of cemented backfill and its reasonable match with rock mass," Transactions of Nonferrous Metals Society of China, vol. 25, no. 3, Article ID 63684, pp. 954-959, 2015.

[32] C.-P. Zhang, K.-H. Han, Q. Fang, and D.-L. Zhang, "Functional catastrophe analysis of collapse mechanisms for deep tunnels based on the Hoek-Brown failure criterion," Journal of Zhejiang University: Science A, vol. 15, no. 9, pp. 723-731, 2014.

[33] J. Pei-Jian, W. En-Yuan, H. Ning, and W. Si-Heng, "Catastrophe progression method on forecast of rock burst," Disaster Advances, vol. 6, no. 7, pp. 34-38, 2013.

[34] Y. Pan and Z.-G. Zhao, "Analysis of main shock of thrust fault earthquake by catastrophe theory," Applied Mathematics and Mechanics-English Edition, vol. 33, no. 7, pp. 845-864, 2012.

[35] W.-J. Yao, Y.-Z. Qiu, and Z.-K. Chen, "Ultimate bearing capacity analysis of a super-long rock-socketed filling pile based on catastrophe theory," Advances in Structural Engineering, vol. 13, no. 2, pp. 331-338, 2010.

[36] Y. Pan and A.-W. Li, "Fold catastrophe model of strike-slip fault earthquake," Applied Mathematics and Mechanics-English Edition, vol. 31, no. 3, pp. 349-362, 2010.

[37] S. Y. Wang, K. C. Lam, S. K. Au, C. A. Tang, W. C. Zhu, and T. H. Yang, "Analytical and numerical study on the pillar rockbursts mechanism," Rock Mechanics and Rock Engineering, vol. 39, no. 5, pp. 445-467, 2006. 


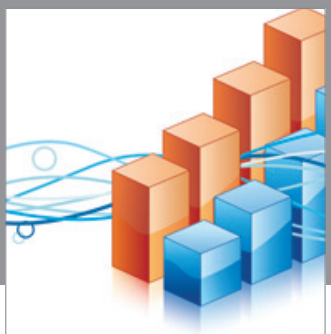

Advances in

Operations Research

vatem alat4

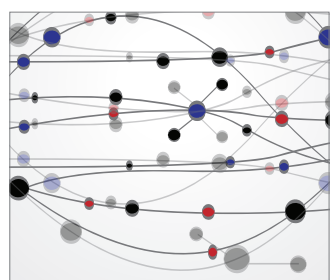

\section{The Scientific} World Journal
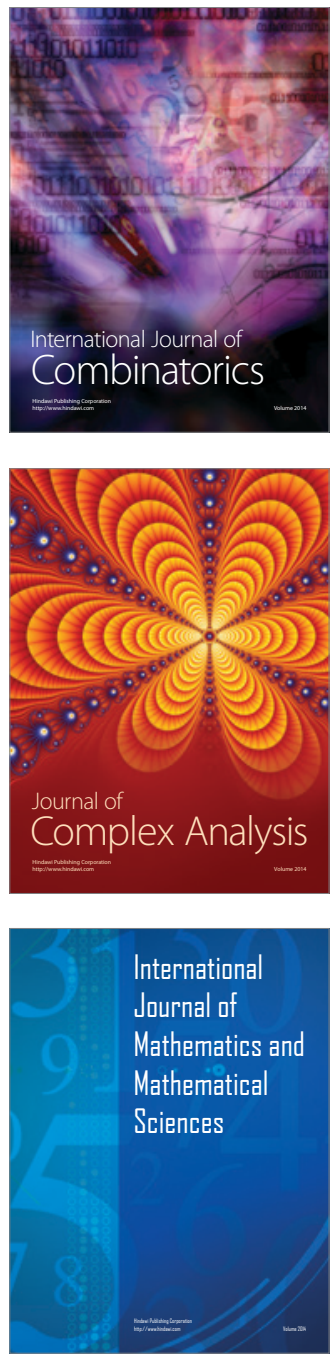
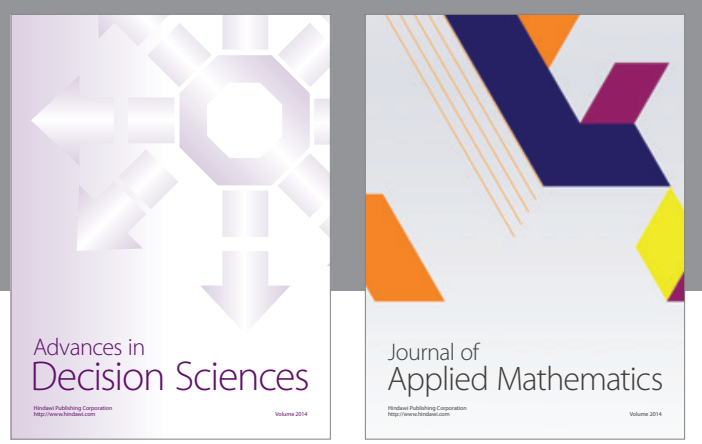

Algebra

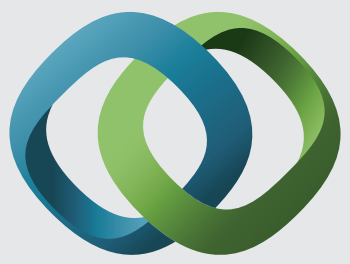

\section{Hindawi}

Submit your manuscripts at

http://www.hindawi.com
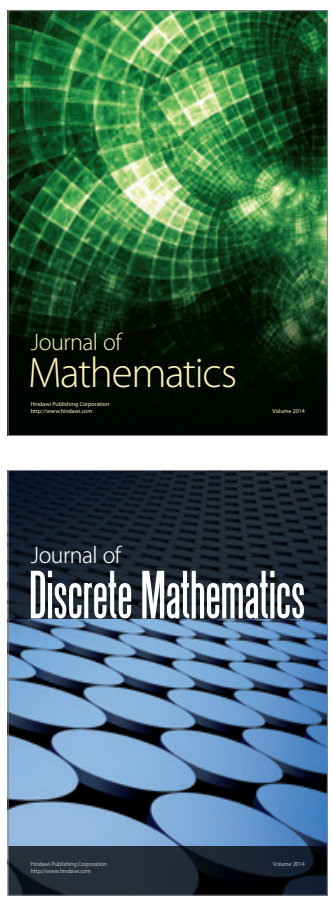

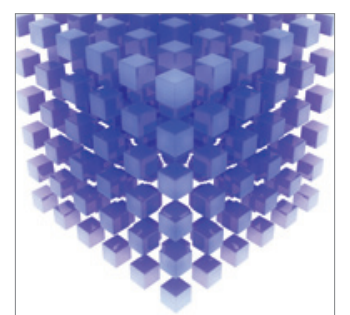

Mathematical Problems in Engineering
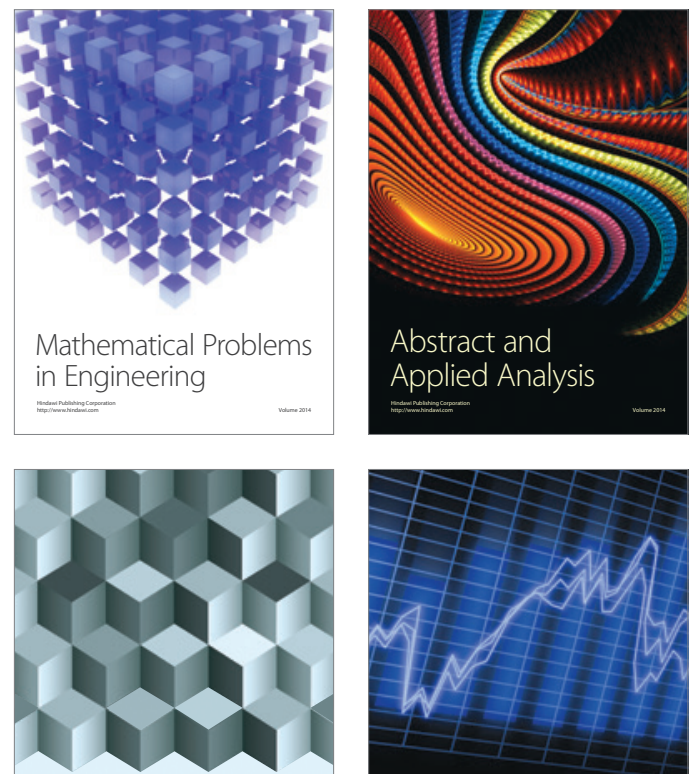

Journal of

Function Spaces

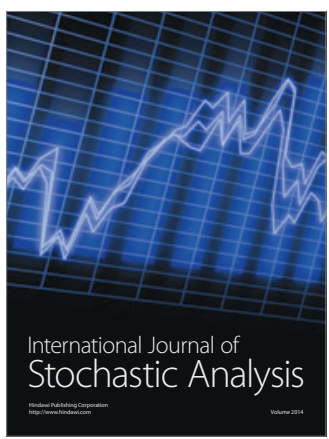

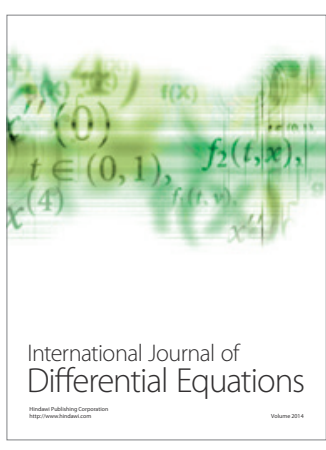
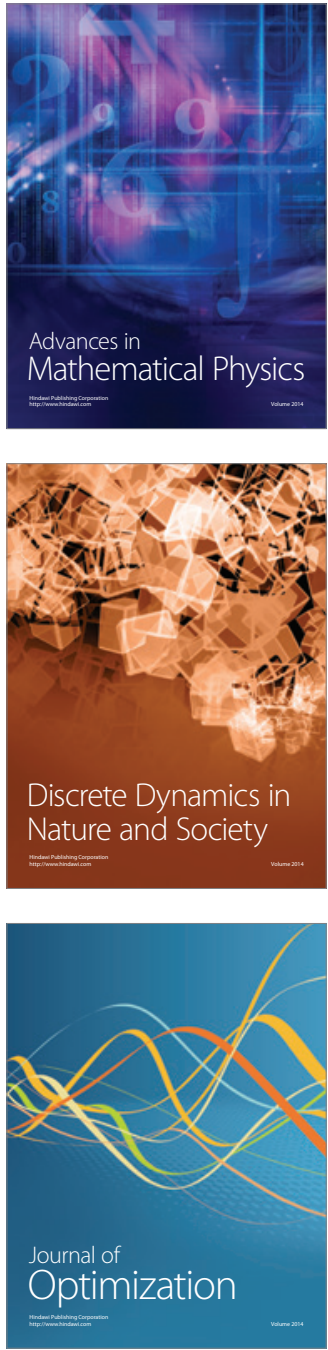